\title{
Pré-oxidação e adsorção em carvão ativado granular para remoção dos herbicidas Diuron e Hexazinona de água subterrânea
}

\section{Preoxidation and adsorption in granular activated carbon for the removal of Diuron and Hexazinone from groundwater}

\author{
Angela Di Bernardo Dantas \\ Engenheira Civil. Mestre e Doutora em Hidráulica e Saneamento pela Escola de Engenharia de São Carlos (EESC-USP). Professora da Universidade \\ da Associação de Ensino de Ribeirão Preto (Unaerp)
}

\section{Cristina Filomena Pereira Rosa Paschoalato}

Engenheira Química. Mestre e Doutora em Hidráulica e Saneamento pela Escola de Engenharia de São Carlos (EESC-USP). Professora da Universidade da Associação de Ensino de Ribeirão Preto (Unaerp)

\section{Renata Rueda Ballejo}

Bacharel em Química com Complementação Tecnológica pela Universidade Estadual Paulista "Júlio de Mesquita Filho" (Unesp). Mestre em Tecnologia Ambiental pela Associação de Ensino de Ribeirão Preto (Unaerp)

\section{Luiz Di Bernardo}

Professor Titular Aposentado do Departamento de Hidráulica e Saneamento da Escola de Engenharia de São Carlos (EESC-USP)

\section{Resumo}

O cultivo da cana-de-açúcar exige a utilização de herbicidas, destacando-se o Diuron e a Hexazinona. Alguns dos poços de abastecimento de Ribeirão Preto (SP) construídos no Aquífero Guarani estão situados em pontos de recarga, e a presença de solo de textura arenosa nessas áreas aumenta a vulnerabilidade da água subterrânea à contaminação por herbicidas. Neste trabalho foram monitorados alguns poços localizados na área de recarga e estudou-se a remoção de Diuron e Hexazinona por meio da adsorção em carvão ativado granular (CAG) e da pré-oxidação com cloro e dióxido de cloro em uma instalação piloto de escoamento contínuo. Verificou-se que o tempo de saturação do CAG no ensaio com a pré-oxidação foi inferior ao obtido no ensaio sem a pré-oxidação com ambos os oxidantes, possivelmente pela formação de subprodutos que competiram com a adsorção dos herbicidas.

Palavras-chave: aquífero Guarani; herbicida; Diuron; Hexazinona; carvão ativado granular; cloro; dióxido de cloro

\begin{abstract}
The cultivation of sugarcane demands the use of herbicides such as Diuron and Hexazinone. Some supply wells from Ribeirão Preto, SP, Brazil, built in the Guarani Aquifer are located in recharge points, and the presence of sandy Quartzarenic Neosol in these areas increases the vulnerability of the groundwater to contamination from herbicides This paper reports the water quality monitored in some wells located in the recharge area and the removal of Diuron and Hexazinone by means of adsorption in granular activated carbon (GAC), preceded or not by preoxidation with chlorine and chlorine dioxide in a pilot plant. The results indicated that Diuron was more strongly adsorbed than Hexazinone and that the saturation time of the GAC in the test with preoxidation was shorter than in the test without preoxidation, which may have occurred mainly due to the formation of by-products that competed with the adsorption of the herbicides.
\end{abstract}

Keywords: Guarani aquifer; herbicide; Diuron; Hexazinone; granular activated carbon; chlorine; chlorine dioxide. 


\section{Introdução}

A cultura de cana-de-açúcar vem aumentando no Brasil devido à crescente demanda de álcool usado como combustível e à exportação de açúcar e álcool. De acordo com o primeiro levantamento da safra brasileira de cana de açúcar 2007/2008, a estimativa da produção nacional de cana-de-açúcar na safra 2007/2008 foi de 528 milhões de toneladas, superior à safra de 2006/2007 em 11,2\% (IEA, 2007).

As áreas agrícolas favorecem a contaminação de águas subterrâneas e superficiais por fontes difusas decorrente do uso de grande quantidade de fertilizantes e agrotóxicos, tais como Ametrina, Diuron, Tebutiuron e Hexazinona (JACOMINI, 2006). Silva (2004) cita esses herbicidas, além de Metribuzin, Halosulfuron, Clomazone, Ametrina, 2,4-D, Imazapic, Fluazifop-p-butil, como os mais recomendados nos vários estágios de produção de cana-de-açúcar.

Depois de serem aplicados sobre o solo e/ou plantas, os agrotóxicos são submetidos a uma série de processos biológicos e não biológicos que podem implicar na degradação ou transporte através da atmosfera, dos solos, dos organismos e, particularmente, da água. O caminho e a extensão deste transporte são diferentes em função do composto (GICQUEL, 1998). Para avaliação da presença de agrotóxicos em amostras ambientais, é de grande importância o conhecimento de suas propriedades físicas e químicas, tais como solubilidade, grau de adsorção no solo $\left(\mathrm{K}_{\mathrm{OC}}\right)$, meia-vida no solo $\left(\mathrm{DT}_{50}\right)$ e taxa de volatilização. Essas características, associadas às diferentes características ambientais, caracterizam os agrotóxicos no que diz respeito à persistência, à toxicidade relacionada aos efeitos na saúde humana e à bioacumulação (PESSOA; SCRAMIN; CHAIM, 2007).

Os resultados de inúmeros trabalhos têm revelado a presença de níveis alarmantes de agrotóxicos e seus produtos de degradação em solos e águas superficiais e subterrâneas. O uso indiscriminado destes produtos levou à contaminação dos solos de mais da metade dos estados americanos, onde índices acima de $5.000 \mathrm{mg} . \mathrm{L}^{-1}$ de atrazina, $3.900 \mathrm{mg} . \mathrm{L}^{-1}$ de diuron e $1.900 \mathrm{mg} . \mathrm{L}^{-1}$ de parathion foram descritos na literatura (PARSONS; WITT, 1989).

A Associação Brasileira de Águas Subterrâneas (ABAS) define o aquífero Guarani como um dos maiores reservatórios de água doce do planeta. O aquífero Guarani é o maior manancial de água doce subterrânea transfronteiriço do mundo. No território brasileiro, ele abrange os Estados de Goiás, Mato Grosso do Sul, Minas Gerais, São Paulo, Paraná, Santa Catarina e Rio Grande do Sul.

No Estado de São Paulo, o aquífero é explorado por mais de 1.000 poços e ocorre em uma faixa no sentido sudoeste-nordeste. Sua área de recarga ocupa cerca de $17.000 \mathrm{~km}^{2}$ onde se encontra a maior parte dos poços. A área de recarga é definida como um local por onde a água da chuva se infiltra para as camadas profundas do solo, atingindo a zona saturada. Essa é a área mais vulnerável e deve ser objeto de programas de planejamento e gestão ambiental permanentes para evitar a contaminação da água subterrânea. Por ser um aquífero de extensão continental com característica de confinamento, sua dinâmica ainda é pouco conhecida, havendo uma necessidade de maiores estudos para seu entendimento, de forma a possibilitar uma utilização mais racional e o estabelecimento de estratégias de preservação mais eficientes (BORGHETTI; BORGHETTI; FILHO, 2004).

Todo o abastecimento da população de Ribeirão Preto é feito por água subterrânea proveniente do aquífero Guarani. Atualmente, a cidade possui cem poços artesianos em funcionamento. Alguns desses poços encontram-se em pontos de recarga do aquífero, e a presença de solo de textura arenosa nessas áreas aumenta a vulnerabilidade da água subterrânea à exposição de herbicidas aplicados no solo (GOMES; SPADOTTO; LANCHOTTE, 2001).

Desde 1994, a Empresa Brasileira de Pesquisa Agropecuária (Embrapa) vem monitorando a qualidade da água do aquífero Guarani em áreas agrícolas no Brasil (GOMES, SPADOTTO; LANCHOTTE, 2001; PESSOA et al, 2003; CERDEIRA et al, 2005). Na região de Ribeirão Preto (SP), foram encontrados traços de Tebutiuron na área de recarga desse aquífero no período de 1996 a 1999 (GOMES, SPADOTTO; LANCHOTTE, 2001).

Os resultados obtidos por Coutinho et al (2005) mostraram que o cultivo intensivo de soja e milho na área de recarga do aquífero Guarani pode ser extremamente arriscado no que diz respeito à qualidade da água subterrânea, mesmo sob plantio direto. Os autores recomendam que as zonas de recarga sejam consideradas área de proteção permanente ou cultivada sob sistemas de produção agroecológicos com baixo aporte de insumos.

A Portaria do Ministério da Saúde no 518 (BRASIL, 2004) não faz menção aos herbicidas Diuron e Hexazinona. Existem algumas normas e padrões internacionais que limitam a concentração máxima dessas substâncias na água tratada como, por exemplo, a canadense, com concentração máxima de Diuron de $150 \mu \mathrm{g} . \mathrm{L}^{-1}$, e a australiana, com concentração máxima de Hexazinona de $300 \mu \mathrm{g} . \mathrm{L}^{-1}$ (HAMILTON et al, 2003).

Segundo Chen e Young (2008), o Diuron é um dos herbicidas mais usados na Califórnia, EUA, e tem sido frequentemente detectado nas águas de abastecimento do estado. O estudo sugere que o Diuron pode ser um precursor da formação da nitrosodimetilamina (NDMA). A NDMA é um composto da família das $\mathrm{N}$-nitrosaminas com elevado potencial carcinogênico. De acordo com Mitch et al (2003), até recentemente havia a preocupação com a presença de NDMA somente em alimentos e no ar poluído. Entretanto, os autores relataram que tem aumentado a preocupação com a ocorrência do NDMA em água potável como resultante de reações durante a cloração ou por contaminação com efluentes industriais. Chen e Young (2008) quantificaram o potencial de formação de NDMA de soluções aquosas de Diuron em diferentes condições de aplicação de cloro e de cloraminas. A formação de NDMA foi consistentemente observada mesmo na ausência de amônia. Quantidade significativa de NDMA (170 ng. $\left.\mathrm{L}^{-1}\right)$ foi 
formada durante a oxidação de solução de Diuron com dicloramina, com concentração de Diuron em torno de $20 \mu \mathrm{g} . \mathrm{L}^{-1}$, valor típico encontrado na Califórnia.

$\mathrm{Na}$ Tabela 1 são apresentadas algumas informações técnicas do herbicida comercial composto por Diuron e Hexazinona.

Os agrotóxicos (herbicidas, fungicidas e inseticidas) podem ser absorvidos por via oral, dérmica ou respiratória. Quando ingeridos em doses altas, podem acarretar lesões em órgãos onde são metabolizados (fígado e rins) e, eventualmente, depressão do sistema nervoso central (ANVISA, 2006). Segundo dados do Pesticide Management Education Program (2008), para o Diuron, o DL50 (teste de letalidade de $50 \%$ da população) em 48 horas para peixes está compreendido na faixa de 4,3 a $42 \mathrm{mg} \cdot \mathrm{L}^{-1}$, e para invertebrados na faixa de 1,0 a 2,5 mg. $\mathrm{L}^{-1}$. Para a Hexazinona, os valores do DL50 em 96 horas para peixes variam de 150 a $320 \mathrm{mg} \cdot \mathrm{L}^{-1}$.

A adsorção de compostos orgânicos em carvão ativado é uma das tecnologias usadas em tratamento de água de abastecimento e no tratamento de efluentes industriais (NAJM et al, 1991; PETRIE et al, 1993; COELHO; VAZZOLER, 2005; KURODA et al, 2005; SILVA; BRANDÃO; PIRES JÚNIOR, 2007; VERAS; BRANDÃO, 2007; PIZA, 2008; RUEDA, 2008).

Piza (2008) caracterizou e estudou a eficiência de adsorção de carvões ativados pulverizados (CAP) e de carvões ativados granulares (CAG) de diferentes matérias-prima e fabricantes na remoção de Diuron e Hexazinona de águas contaminadas. O autor concluiu que o CAP e o CAG de Babaçu foram os mais eficientes. Os resultados obtidos também mostraram maior eficiência na adsorção do herbicida Diuron em detrimento da Hexazinona.

Di Bernardo e Dantas (2005) e Shwarzenbach et al (2006) mencionam que várias tecnologias têm sido usadas para a remoção de micropoluentes na presença de matrizes orgânicas e inorgânicas na água, destacando-se a oxidação química, a adsorção, a sedimentação e a filtração. Um dos desafios do tratamento de água é o projeto de unidades de tratamento capazes de remover diversos micropoluentes com características químicas diferentes, possivelmente presentes concomitantemente na água.

No presente trabalho, foi avaliada a remoção dos herbicidas Hexazinona e Diuron de água subterrânea por adsorção em carvão ativado granular, precedida ou não pela pré-oxidação com cloro e dióxido de cloro e verificação da formação de subprodutos orgânicos halogenados (SOH) nos ensaios com a pré-oxidação. Adicionalmente, foi monitorada a qualidade da água de quatro poços artesianos em funcionamento de Ribeirão Preto, sendo dois deles localizados na área de recarga e próximos a plantações de cana-de-açúcar.

\section{Material e métodos}

\section{Quantificação de Diuron e Hexazinona}

Os herbicidas Diuron e Hezaxinona foram quantificados pela técnica analítica de cromatografia a gás com detector de nitrogênio e fósforo (CG - DNP); a metodologia foi adaptada de USEPA 507 (1995A). Os limites de quantificação obtidos foram 0,1 $\mu \mathrm{g} \cdot \mathrm{L}^{-1}$ para o Diuron e 1,0 $\mu \mathrm{g} . \mathrm{L}^{-1}$ para a Hexazinona.

Os subprodutos orgânicos halogenados ( $\mathrm{SOH}$ ) foram determinados por cromatografia a gás com detector de captura de elétrons, de acordo com a técnica recomendada pelo método 551.1 USEPA (1995B). Os seguintes subprodutos foram investigados: (i) trialometanos: clorofórmio, bromodiclorometano, dibromoclorometano, bromofórmio; (ii) haloacetonitrilas: dicloroacetonitrila, tricloroacetonitrila, dibromoacetonitrila, tribromoacetonitrila, bromocloroacetonitrila; (iii) halopicrinas: cloropicrina; (iv) haloacetonas: 1,1-dicloropropanona, 1,1,1-tricloropropanona; (v) tricloroacetaldeído (cloro hidrato). O limite de quantificação obtido foi $0,1 \mu \mathrm{g} / \mathrm{L}$ para todos os compostos $\mathrm{SOH}$

Tabela 1 - Informações técnicas dos herbicidas Diuron e Hexazinona

\begin{tabular}{|c|c|c|}
\hline & Hexazinona & Diuron \\
\hline Nome químico & $\begin{array}{l}\text { 3-ciclohexil-6-Dimetilamino-1-metil-1,3,5-triazina- } \\
\text { 2,4(1H,3H)-diona }\end{array}$ & 3-(3,4-diclorofenil)-1,1-dimetilureia \\
\hline Fórmula bruta & $\mathrm{C}_{12} \mathrm{H}_{20} \mathrm{~N}_{4} \mathrm{O}_{2}$ & $\mathrm{C}_{9} \mathrm{H}_{10} \mathrm{Cl}_{2} \mathrm{~N}_{2} \mathrm{O}$ \\
\hline Grupo químico & Triazinona & Ureia \\
\hline Classe & Herbicida & Herbicida \\
\hline Classificação tóxica & Classe III & Classe III \\
\hline Uso agrícola & $\begin{array}{l}\text { Aplicação em pré e pós-emergência das plantas } \\
\text { infestantes na cultura de cana-de-açúcar }\end{array}$ & $\begin{array}{l}\text { Aplicação em pré e pós-emergência das plantas } \\
\text { infestantes na cultura de cana-de-açúcar }\end{array}$ \\
\hline Estrutura química & $\mathrm{CH}_{3}$ & $\mathrm{H}_{3} \mathrm{C}$ \\
\hline
\end{tabular}




\section{Monitoramento da qualidade da água dos poços}

Os poços monitorados foram selecionados sob orientação do Departamento de Água e Esgoto de Ribeirão Preto (DAERP). Foram avaliados quatro poços com frequência de amostragem quinzenal por um período de dez meses. Os poços monitorados foram denominados:

- Poço 1: localizado em zona de recarga, com ausência de cultura de cana-de-açúcar;

- Poço 2: localizado em rocha, próximo à cultura de cana-deaçúcar;

- Poço 3: localizado em zona de recarga, próximo à cultura de cana-de-açúcar

- Poço 4: localizado em zona de recarga, próximo à cultura de cana-de-açúcar.

\section{Preparação da água de estudo}

Nesta pesquisa, foi preparada uma água sintética com características similares às do Rio Pardo em turbidez e cor aparente, contaminada na concentração de $50 \mathrm{mg} \cdot \mathrm{L}^{-1}$ do produto comercial, composto pelos ativos Diuron (46,8\% em massa/massa), Hexazinona (13,2\% em massa/massa) e o restante de inertes. Essa concentração do produto comercial foi fixada com base nos resultados dos bioensaios em ratos realizados por Trimailovas et al (2008).

\section{Instalação piloto}

Foi construída uma instalação piloto (IP) de escoamento contínuo composta por tanque para armazenamento da água de estudo

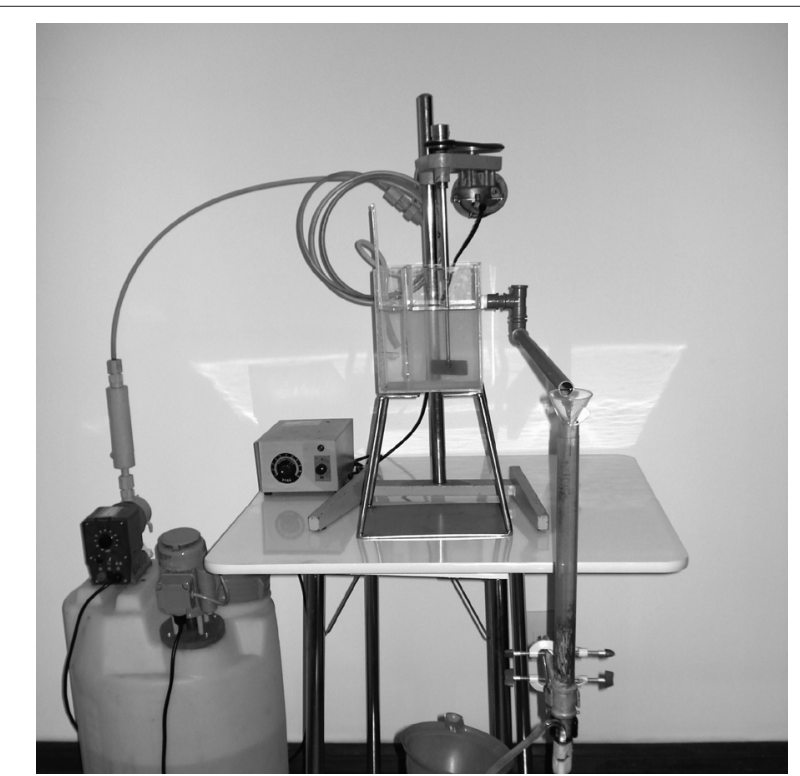

(60 L), bomba dosadora para recalque da água de estudo à IP, câmara de pré-oxidação com agitador mecânico e coluna de carvão ativado granular. A coluna de CAG foi montada em coluna de vidro com diâmetro interno de 2,0 mm e a altura útil de CAG foi fixada em $20 \mathrm{~cm}$. A câmara de pré-oxidação foi construída em acrílico, com tempo médio de detenção de 45 minutos para a vazão de estudo de 2,0 L.h ${ }^{-1}$. As vazões das soluções de cloro e de dióxido de cloro (oxidantes) foram fixadas em função dos resultados dos ensaios de demanda. $\mathrm{Na}$ Figura 1 é apresentada uma foto e um esquema da IP.

\section{Carvão ativado granular}

O CAG de Babaçu utilizado neste estudo foi pesquisado e caracterizado por Piza (2008). Algumas das suas características são: Número de Iodo $=1030 \mathrm{mg} \cdot \mathrm{g}^{-1}$; Índice de Azul de Metileno $=170$ $\mathrm{mL} \cdot \mathrm{g}^{-1}$; área específica BET $=118,6 \mathrm{~m}^{2} \cdot \mathrm{g}^{-1}$.

\section{Ensaios para determinação das dosagens dos oxidantes}

Realizaram-se ensaios prévios em mesa agitadora visando à determinação das dosagens de cloro e de dióxido de cloro para uso na pré-oxidação da água de estudo. Os ensaios de pré-oxidação com o cloro e com o dióxido de cloro foram realizados com tempo de contato de 30 minutos e dosagens variando entre 0,1 e 2,5 mg. $\mathrm{L}^{-1}$ de cloro (solução de hipoclorito de cálcio) e de 0,25 a 1,5 mg..-1 de dióxido de cloro (gerado a partir de clorato de sódio, peróxido de hidrogênio e de ácido sulfúrico).

O critério para a escolha das dosagens de cloro e de dióxido de cloro foi o residual do oxidante em torno de $0,1 \mathrm{mg} \cdot \mathrm{L}^{-1}$, para que

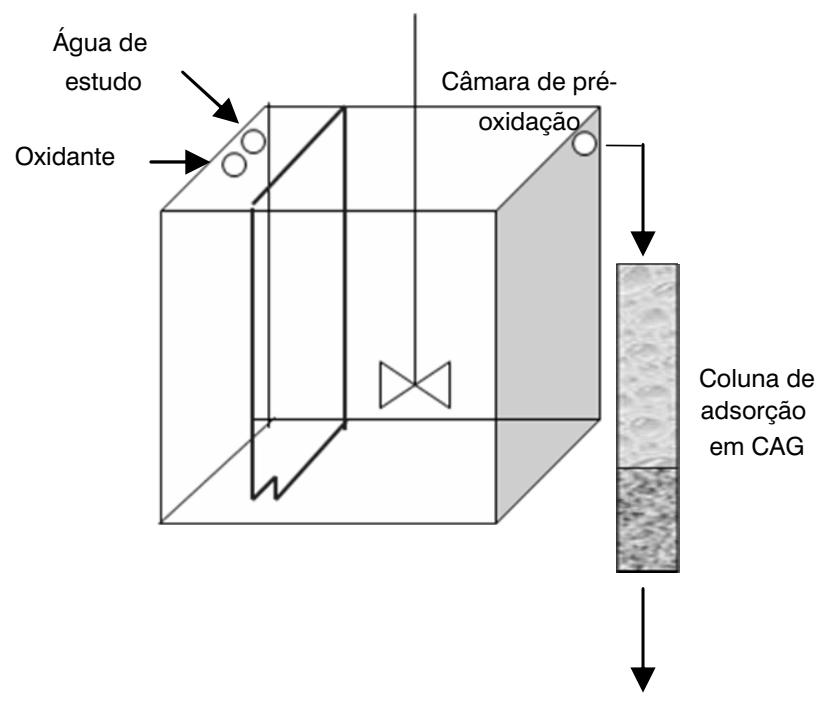

Água final

Figura 1 - Foto e esquema da instalação piloto 
não houvesse interferência do residual do oxidante na adsorção dos herbicidas no carvão ativado. Para medição dos residuais de cloro e de dióxido de cloro, foi usado o método espectrofotométrico com uso de DPD (n,n-dietil-p-fenileno-diamina), com adição de glicina para a leitura do residual de dióxido de cloro.

\section{Ensaios na instalação piloto}

Foram realizados três ensaios, conforme características listadas a seguir.

- Ensaio 1: adsorção em CAG

- Vazão da água de estudo: 2,0 L.h ${ }^{-1}$

- Duração do ensaio: 54 horas;

- Parâmetros de controle: Diuron e Hexazinona do efluente da coluna CAG.

- Ensaio 2: pré-oxidação com cloro e adsorção em CAG

- Vazão da solução de cloro: 0,3 L.h.'

- Vazão da água de estudo: 2,0 L.h ${ }^{-1}$

- Duração do ensaio: 24 horas;

- Parâmetros de controle: residual de cloro e SOH do efluente da câmara de pré-oxidação e Diuron, Hexazinona e SOH do efluente da coluna de CAG

- Ensaio 3: pré-oxidação com dióxido de cloro e adsorção em CAG

- Vazão da solução de dióxido de cloro: 0,3 L.h-1

- Vazão da água de estudo: 2,0 L.h ${ }^{-1}$

- Duração do ensaio: 14 horas;

- Parâmetros de controle: residual de dióxido de cloro e SOH do efluente da câmara de pré-oxidação e Diuron, Hexazinona e SOH do efluente da coluna de CAG.

\section{Resultados e discussão}

\section{Monitoramento da qualidade da água dos poços}

Durante o período monitorado, foram encontrados nas amostras coletadas somente do Poço 3 (localizado em zona de recarga, próximo à cultura de cana-de-açúcar) traços de Diuron no mês de maio de 2007 e traços de Hexazinona nos meses de maio de 2007 e fevereiro de 2008, com concentrações na faixa de 0,26 a 7,12 $\mu \mathrm{g} . \mathrm{L}^{-1}$, valores muito inferiores aos recomendados por padrões internacionais considerados como referência neste trabalho (padrão canadense: concentração máxima de Diuron de $150 \mu g . \mathrm{L}^{-1} \mathrm{e}$ padrão australiano: concentração máxima de Hexazinona de $300 \mu \mathrm{g} . \mathrm{L}^{-1}$ ) e próximos aos limites de detecção da metodologia empregada. Esses resultados confirmam a vulnerabilidade das águas subterrâneas e a necessidade de um monitoramento intensificado dos poços localizados em zona de recarga e próximos a áreas agrícolas.

\section{Ensaios para determinação das dosagens dos oxidantes}

Nas Figuras 2 e 3 são apresentados os resultados dos residuais dos oxidantes cloro e dióxido de cloro, respectivamente, na pré-oxidação da água de estudo com 30 minutos de tempo de contato.

Com base nos resultados das Figuras 2 e 3, as dosagens de cloro e de dióxido de cloro fixadas para a realização dos ensaios na IP foram de 0,3 mg. $\mathrm{L}^{-1}$ e de 0,5 mg. $\mathrm{L}^{-1}$, respectivamente, sendo que em ambos os casos o residual do oxidante resultou em torno de $0,1 \mathrm{mg} . \mathrm{L}^{-1}$.

\section{Ensaios na instalação piloto}

Os resultados dos ensaios 1, 2 e 3 realizados na instalação piloto (IP) são apresentados nas Figuras 4, 5 e 6, respectivamente. Nestas figuras foram destacados os tempos em que foram iniciados os transpasses dos herbicidas na coluna de CAG. O transpasse é definido como o aumento contínuo da concentração do contaminante no efluente da coluna de CAG, indicando sua saturação.

De acordo com os resultados da Figura 4, apenas de adsorção em CAG, o início do transpasse da Hexazinona (em torno de 20 horas) ocorreu antes do início do transpasse do diuron (entre 24 e 30 horas). Estes resultados indicam maior afinidade do CAG usado na adsorção do Diuron, de acordo com os resultados obtidos por Piza

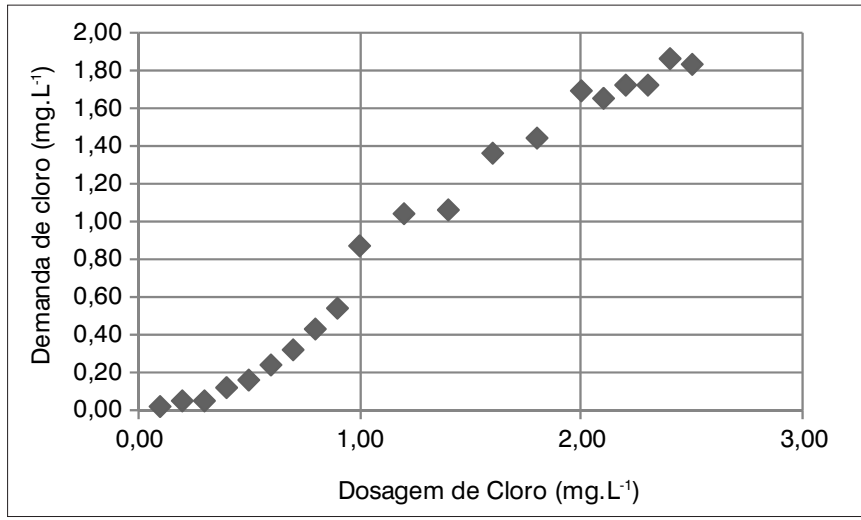

Figura 2 - Demanda de cloro na pré-oxidação da água de estudo

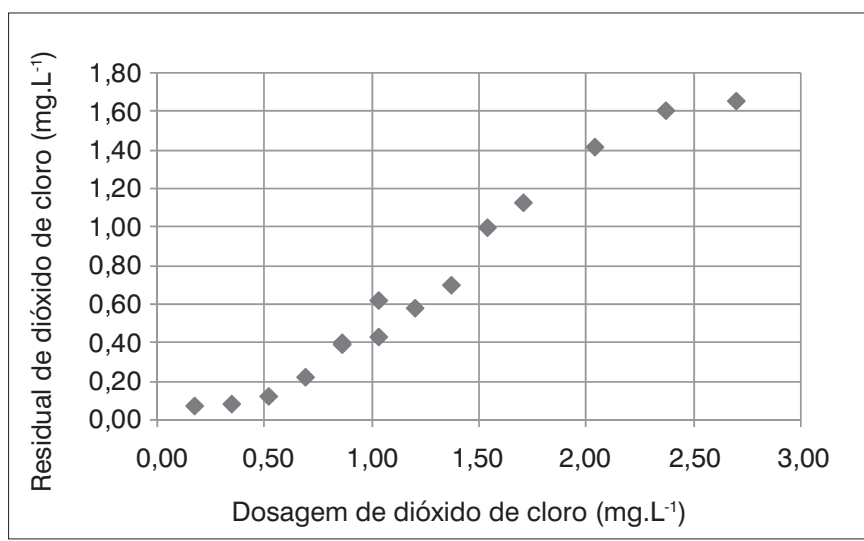

Figura 3 - Demanda de dióxido de cloro na pré-oxidação da água de estudo 


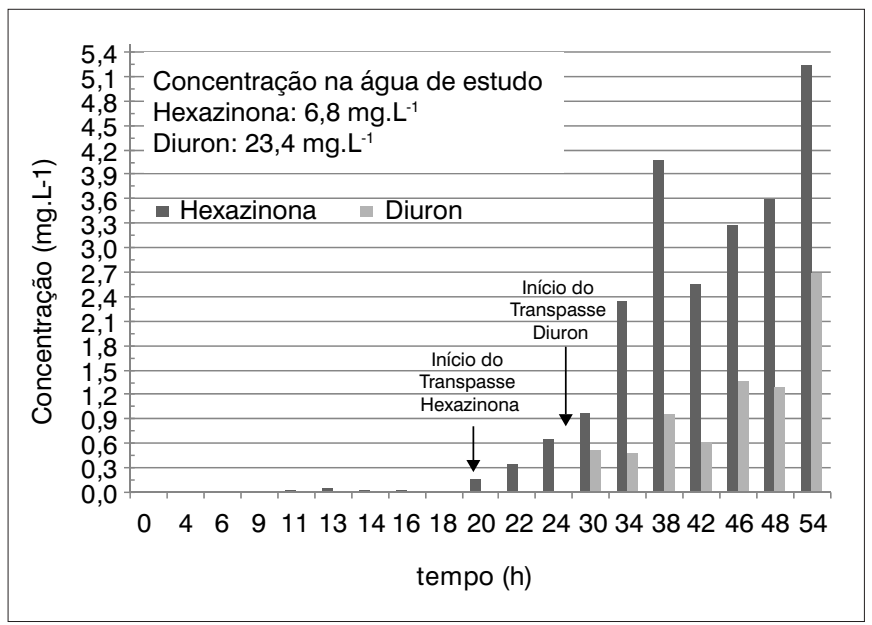

Figura 4 - Concentração de Diuron e de Hexazinona no efluente da coluna de adsorção: resultados do ensaio 1 na instalação piloto (sem a pré-oxidação)

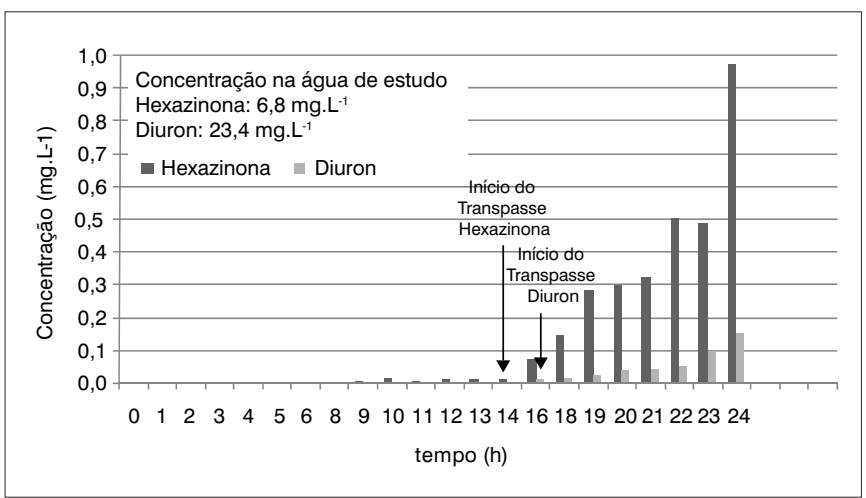

Figura 5 - Concentração de Diuron e de Hexazinona no efluente da coluna de adsorção: resultados do ensaio 2 na instalação piloto (com a pré-oxidação com cloro)

(2008). A partir de 22 horas de funcionamento, as concentrações de Hexazinona no efluente do CAG superaram o valor limite de 300 $\mu \mathrm{g} . \mathrm{L}^{-1}$, e de Diuron a partir de 30 horas, com concentrações superiores a $150 \mu \mathrm{g} . \mathrm{L}^{-1}$.

Nota-se, na Figura 5, que no ensaio 2, o início do transpasse tanto do Diuron quanto da Hexazinona ocorreram antes dos tempos verificados no ensaio 1 , sendo para a Hexazinona por volta de 14 horas e para o Diuron por volta de 16 horas. Os resultados obtidos mostraram que a pré-oxidação da água de estudo com o cloro piorou a eficiência de adsorção do CAG, indicando que pode ter havido competição entre os subprodutos formados da oxidação do Diuron e da Hexazinona ou do cloro residual pelos sítios ativos do CAG. A partir de 18 horas de funcionamento, as concentrações de Hexazinona no efluente do CAG superaram o valor limite de $300 \mu \mathrm{g} . \mathrm{L}^{-1}$, e de Diuron a partir de 24 horas, foram superiores a $150 \mu \mathrm{g} \cdot \mathrm{L}^{-1}$.

Os resultados do ensaio 3 mostraram que a pré-oxidação com o dióxido de cloro piorou ainda mais a eficiência de adsorção do CAG, com os inícios dos transpasses ocorrendo em torno de 6

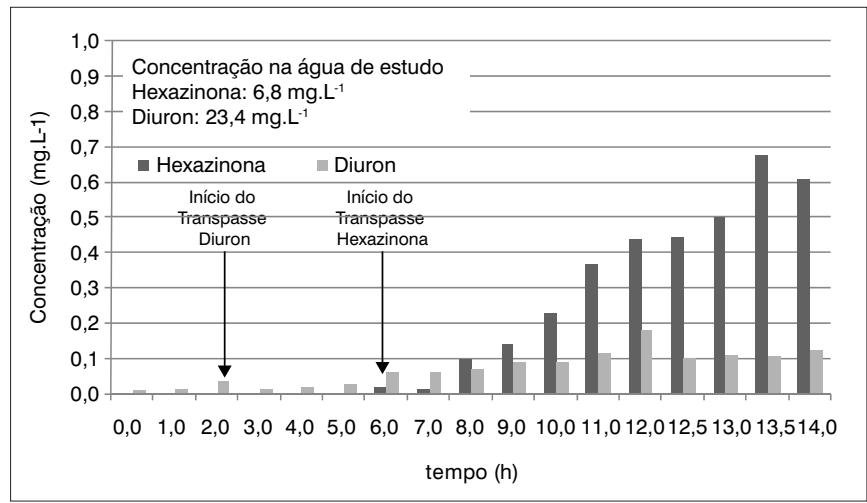

Figura 6 - Concentração de Diuron e de Hexazinona no efluente da coluna de adsorção: resultados do ensaio 3 na instalação piloto (com a pré-oxidação com dióxido de cloro)

horas de funcionamento para a Hexazinona e em torno de 2 horas para o Diuron. A partir de 9 horas de funcionamento, as concentrações de Hexazinona no efluente do CAG superaram o valor limite de $300 \mu \mathrm{g}$. $\mathrm{L}^{-1}$, e de Diuron a partir de 12 horas, foram superiores a $150 \mu \mathrm{g} \cdot \mathrm{L}^{-1}$. Além dos subprodutos formados da oxidação dos herbicidas pelo dióxido de cloro, a eficiência do CAG pode ter piorado devido à presença do clorito na água pré-oxidada, uma vez que em torno de 50 a $70 \%$ do dióxido de cloro aplicado se converte em clorito (RITTMAN, 1996). Segundo Collivignarelli, Sorlini e Belluati (2006), a remoção de clorito pela CAG é feita em duas etapas: adsorção do clorito nos sítios do CAG e redução do clorito para cloreto.

No ensaio com a pré-oxidação com cloro (ensaio 2), houve formação de $90 \mu \mathrm{g} . \mathrm{L}^{-1} \mathrm{de}$ SOH na água pré-oxidada, com predominância do clorofórmio. Após a adsorção em CAG, a concentração total de SOH obtida foi menor do que o limite de detecção $\left(0,1 \mu \mathrm{g} \cdot \mathrm{L}^{-1}\right)$. No ensaio 3 , com a pré-oxidação com o dióxido de cloro, não houve formação de $\mathrm{SOH}$.

Outros subprodutos podem ter sido formados quando foram usados o cloro e o dióxido de cloro em águas contendo Diuron e Hexazinona, conforme dados de Chen e Young (2008), em estudos realizados com o Diuron.

\section{Conclusões}

Os resultados obtidos no monitoramento efetuado nos poços artesianos localizados em diferentes situações de uso e ocupação do solo indicaram a vulnerabilidade das águas subterrâneas e a necessidade de um monitoramento intensificado dos poços localizados em zona de recarga e próximos a áreas agrícolas.

Nas condições em que foram realizados os ensaios na instalação piloto, a pré-oxidação tanto com o cloro quanto com o dióxido de cloro piorou a eficiência de adsorção do CAG para o Diuron e para a Hexazinona. Pode ter havido competição pelos sítios ativos do CAG entre os subprodutos formados da oxidação desses herbicidas, entre 
os residuais dos oxidantes e, no caso do dióxido de cloro, também com o clorito.

$\mathrm{Na}$ ocorrência de contaminação de poços artesianos com os herbicidas mencionados, a adsorção em CAG poderá ser a tecnologia de tratamento empregada para remoção destes compostos.

\section{Agradecimentos}

Os autores agradecem à Financiadora de Estudos e Projetos (Finep) e ao Conselho Nacional de Desenvolvimento Científico e Tecnológico (CNPq) pelo financiamento das pesquisas na rede PROSAB 5.

\section{Referências}

AGÊNCIANACIONAL DE VIGILÂNCIA SANITÁRIA (ANVISA). Informações médicas de urgência nas intoxicações por produtos agrotóxicos. 2006. [On-line]. Disponível em: <http://www.anvisa.gov.br/toxicologia/ informed/paginaoutros.htm>. Acesso em: 14 jul. 2009.

BORGHETTI, N.R.B.; BORGHETTI, J.R.; FILHO, E.F.R. Aqüífero Guarani: a verdadeira integração dos países do MERCOSUL. Curitiba: Maxigráfica, 2004.

BRASIL. Portaria 518, de 25 de março de 2004. Normas e padrão de potabilidade das águas destinadas ao consumo humano. Brasília, DF, 2004.

CERDEIRA, A.L. et al. Effects of sugar cane mechanical harvesting followed by no-tillage crop systems on leaching of triazine herbicides in Brazil. Bulletin of Environmental Contamination and Toxicology, v. 75, n. 4, p. 805-812, 2005

CHEN, W.; YOUNG, T.M. NDMA formation during chlorination and chloramination of aqueous diuron solutions. Environmental Science and Technololy, v. 42, n. 4, p. 1072-1077, 2008

COELHO, E.R.C.; VAZZOLER, H. Capacidade de adsorção frente às isotermas de Langmuir e Freundlich para atrazina em materiais zeolíticos e carbonosos utilizados em tratamento de água na remoção de matéria orgânica natural e sintética. In: $23^{\circ}$ CONGRESSO BRASILEIRO DE ENGENHARIA SANITÁRIA E AMBIENTAL. Anais... Campo Grande, Mato Grosso do Sul: ABES, 2005.

COLLIVIGNARELLI, C.; SORLINI, S.; BELLUATI, M. Chlorite removal with GAC. Journal AWWA, v. 98, n. 12, p. 74-81, 2006.

COUTINHO, C.A.F.B. et al. Pesticidas: mecanismo de ação, degradação e toxidez, Pesticidas: Revista Ecotoxicologia e Meio Ambiente, Curitiba, v. 15, p. 65-72, jan./dez. 2005.

DI BERNADO, L.; DANTAS, A.D.B. Métodos e técnicas de tratamento de água. 2. ed. São Carlos: RiMa, 2005. v. 2.

GICQUEL, L. Curso agrotóxico. Florianópolis: UFSC, 1998

GOMES, M.A.P.F.; SPADOTTO, C.; LANCHOTTE, V.L. Ocorrência do herbicida tebutiurom na água subterrânea da microbacia do córrego Espraiado, Ribeirão Preto, SP. Pesticidas: Revista Ecotoxicologia e Meio Ambiente, Curitiba, v. 11, p. 65-76, jan./dez., 2001.

HAMILTON, D.J. et al. Regulatory limits for pesticides in water. IUPAC Technical Report. Pure and Applied Chemistry, v. 75, n. 8, p. 1123-1155, 2003.
INSTITUTO DE ECONOMIA AGRícOLA (IEA). Defensivos Agrícolas: preços em queda. 2007. [On-line]. Disponível em http://www.iea.sp.gov. br/out/anuario.php Acesso em: 1 dez. 2007

JACOMINI, A.E. Estudo da presença de herbicida ametrina em águas, sedimentos e moluscos, nas bacias hidrográficas do Estado de São Paulo. 113 f. Tese (Doutorado) - Faculdade de Filosofia, Ciências e Letras de Ribeirão Preto, USP, Ribeirão Preto, São Paulo, 2006.

KURODA, E.K. et al. Caracterização e escolha do tipo de carvão ativado a ser empregado no tratamento de águas contendo microcistinas. In: $23^{\circ}$ CONGRESSO BRASILEIRO DEENGENHARIASANITÁRIAEAMBIENTAL. Anais... Campo Grande, Mato Grosso do Sul: ABES, 2005

MITCH, W.A. et al. Nitrosodimethylamine (NDMA) as a drinking water contaminant: a review. Environmental Engineering Science, v. 1, n. 20 p. $389-404,2003$

NAJM, I.N. et al. Using powdered activated carbon: A critical review. Journal AWWA, v. 83, n. 1, p. 65-76, 1991

PARSONS, B.; WITT, J.M. Pesticides in groundwater in the USA. A report of a 1988 survey of US states. Oregon: Oregon State University Extension Service, 1989

PESSOA, M.C.P.Y. et al. Identificação de áreas de exposição ao risco de contaminação de águas subterrâneas pelos herbicidas atrazina, diuron e tebuthiuron. Pesticidas: Revista Ecotoxicologia e Meio Ambiente, Curitiba, v. 13, p. 111-122, jan./dez. 2003.

PESSOA, M.C.P.Y.; SCRAMIN, S; CHAIM, A. Avaliação do potencial de transporte de agrotóxicos usados no Brasil por modelos screening e planilha eletrônica. Boletim de Pesquisa e Desenvolvimento. Jaguariúna: Embrapa Meio Ambiente, 2007.

PESTICIDE MANAGEMENT EDUCATION PROGRAM. Pesticides. 2008. [On-line]. Disponível em: http://pmep.cce.cornell.edu/profiles/extoxnet. Acesso em: 14 jul. 2009.

PETRIE, A.J. et al. The effectiveness of water treatment process for removal of herbicides. The Science of the Total Environment, v. 117, n.1, p. 80-100, 1993 .

PIZA, A.V.T. Estudo da capacidade de adsorção dos herbicidas diuron e hexazinona em carvões ativados. 185 f. Dissertação (Mestrado em Tecnologia Ambiental) - Centro de Ciências Exatas, Naturais e Tecnologias, UNAERP, Ribeirão Preto, São Paulo, 2008.

RITTMAN, D. Advantages of chlorite reduction with ferrous iron. Bulletin EKA CHEMICALS, 1996. 
RUEDA, R.B. Pré-oxidação e adsorção em carvão ativado granular para remoção de herbicidas diuron e hexazinona de águas subterrâneas. 175 f. Dissertação (Mestrado em Tecnologia Ambiental) - Centro de Ciências Exatas, Naturais e Tecnologias, UNAERP, Ribeirão Preto, São Paulo, 2008.

SCHWARZENBACH, R.P. et al. Behaviour of organic compounds during infiltration of river water to groundwater: field studies. Enviromental Science and Techonology, v. 17, n. 8, p. 472-479, 2006.

SILVA, C.L. Análise da vulnerabilidade ambiental aos principais pesticidas recomendados para os sistemas de produção de algodão, arroz, café, cana-de-açúcar, citros, milho e soja. 135 f. Dissertação (Mestrado em Engenharia Agrícola) - Faculdade de Engenharia Agrícola, Unicamp, Campinas, São Paulo, 2004.

SILVA, A.S.; BRANDÃO, C.C.S.; PIRES JÚNIOR, O.R. Remoção de saxitoxinas por diferentes tipos de carvão ativado em pó produzidos no Brasil. In: $24^{\circ}$ CONGRESSO BRASILEIRO DE ENGENHARIA SANITÁRIA E AMBIENTAL. Anais... Belo Horizonte: ABES, 2007.
TRIMAILOVAS, M.R. et al. Avaliação da toxicidade e da mutagenicidade de águas contaminadas com os herbicidas diuron e hexazinona. In: XXXI CONGRESSO INTERAMERICANO DE ENGENHARIA SANITÁRIA E AMBIENTAL. Anais... Santiago, Chile: ABES, 2008.

UNITED STATES ENVIRONMENTAL PROTECTION AGENCY (USEPA). Determination of nitrogen and phosphorus containing pesticides in water by gas chromatography with a nitrogen-phosphorus detector. Method 507 Revision 2.1. Ohio, USA, 1995A.

Method 551.1. Determination of chlorination disinfection byproducts, chlorinated solvents, and halogenated pesticides/herbicides in drinking water by liquid-liquid extracion and gas chromatography with electron-capture detection. CD-ROM. Ohio, USA, 1995B.

VERAS, D.F.; BRANDÃO, C.C.S. Remoção do perturbador endócrino17 estradiol por diferentes tipos de carvão ativado em pó (CAP) produzidos no Brasil: Avaliação em escala de bancada. In: $24^{\circ}$ CONGRESSO BRASILEIRO DE ENGENHARIA SANITÁRIA E AMBIENTAL. Anais... Belo Horizonte: ABES, 2007 